\title{
Baseline airway hyperresponsiveness and its reversible component: role of airway inflammation and airway calibre
}

\author{
M. Ichinose, T. Takahashi, H. Sugiura, N. Endoh, M. Miura, Y. Mashito, K. Shirato
}

Baseline airway hyperresponsiveness and its reversible component: role of airway inflammation and airway calibre. M. Ichinose, T. Takahashi, H. Sugiura, N. Endoh, M. Miura, Y. Mashito, K. Shirato. (C)ERS Journals Ltd 2000.

ABSTRACT: Airway hyperresponsiveness (AHR), in which airway inflammation has been reported to be a key factor, is an important component of asthma. However the precise role of inflammation in AHR is still unclear.

In this report, airway inflammatory changes were assessed using hypertonic salineinduced sputum examination and exhaled nitric oxide analysis, and the relation between AHR to methacholine, airway calibre forced expiratory volume in one second (FEV1) and airway inflammatory indices examined. Furthermore, the changes in these variables were also examined by means of 8 weeks' open uncontrolled inhaled steroid administration $\left(800 \mu \mathrm{g} \cdot\right.$ beclomethasone $\left.\cdot \mathrm{day}^{-1}\right)$.

Asthmatic subjects had higher eosinophil counts and bradykinin concentration in induced sputum and higher exhaled NO levels, and showed AHR to methacholine. Baseline AHR significantly correlated with FEV1 but not with indices of inflammation in sputum or exhaled air. Steroid inhalation therapy was associated with a reduction in eosinophil and bradykinin concentration in sputum and NO levels in exhaled air and an improvement in FEV1 and AHR. The changes in FEV1 and AHR were significantly related to changes in markers in sputum and exhaled air $(p<0.01$ for each).

These results suggest that baseline airway hyperresponsiveness can be predicted from the airway calibre but not from inflammatory parameters in sputum or exhaled air. In contrast, the reversible component of airway hyperresponsiveness appeared to be associated with the reduction in airway inflammation.

Eur Respir J 2000; 15: 248-253.

In asthma, an important component underlying the instability of the airways is airway hyperresponsiveness (AHR), which is the presence of an exaggerated bronchoconstrictor response to a wide variety of exogenous and endogenous stimuli [1]. Although airway inflammatory changes have been reported to be a key factor in AHR, conflicting findings have been obtained by the investigative groups who have studied the relationship between airway inflammation and airway responsiveness [2]. Some groups have shown a strong relationship between the above two phenomena [3-6], whereas others have failed to establish such a relationship [7-11].

Recently, some new noninvasive and highly reproducible methods for the detection of airway inflammatory changes have been developed. One of the new methods is hypertonic saline-induced sputum examination, which can be used in subjects without sputum in the basal condition, enabling airway inflammatory changes to be assessed via inflammatory cell counts and mediator analysis in the sputum [12-14]. Another is exhaled nitric oxide analysis. This technique has also been reported to reveal the inflammatory changes in asthmatic airways $[15,16]$.

The aim of this report is to elucidate the relationship between airway responsiveness and inflammatory parameters. Airway responsiveness was assessed by methacho-
First Dept of Internal Medicine, Tohoku University School of Medicine, Sendai, Japan.

Correspondence: M. Ichinose

First Dept of Internal Medicine

Tohoku University School of Medicine

1-1 Seiryo-machi, Aoba-ku

Sendai 980-8574

Japan

Fax: 81227177156

Keywords: Asthma

bradykinin

eosinophil

nitric oxide

sputum

Received: March 191999

Accepted after revision October 101999 line inhalation challenge, and airway inflammatory changes were analysed via the above-mentioned noninvasive methods. Concerning induced sputum examination, this study focused on bradykinin concentration, which has been reported to be relevant in asthmatic airway inflammation $[17,18]$, as well as on eosinophil counts. Furthermore, the relationship between steroid inhalation-mediated changes in airway inflammatory parameters and in responsiveness were studied.

\section{Methods}

\section{Subjects}

Eighteen patients with asthma took part in the study after giving informed consent. The study was approved by the local ethics committee. All patients satisfied the American Thoracic Society criteria for asthma [19]. The clinical characteristics of these subjects are shown in table 1. Forced expiratory volume in one second (FEV1) was measured using a dry rolling-seal spirometer (OST 80A; Chest Co., Tokyo, Japan). All patients were stable and had been without steroid therapy for $\geq 6$ months before the study. 
Table 1. - Characteristics of study subjects

\begin{tabular}{|c|c|c|c|c|c|c|c|c|c|c|c|c|c|}
\hline \multirow{3}{*}{$\begin{array}{l}\text { Subject } \\
\text { No. }\end{array}$} & \multirow{3}{*}{$\begin{array}{l}\text { Age } \\
\text { yrs }\end{array}$} & \multirow{3}{*}{ Sex } & \multirow{2}{*}{\multicolumn{2}{|c|}{ FEV1 }} & \multirow{2}{*}{\multicolumn{2}{|c|}{ PD35 $\mathrm{mg} \cdot \mathrm{mL}^{-1}$}} & \multirow{2}{*}{\multicolumn{2}{|c|}{$\mathrm{NO}$ ppb }} & \multicolumn{4}{|c|}{ Sputum examination } & \multirow{3}{*}{$\begin{array}{c}\text { Drug } \\
\text { treatment }\end{array}$} \\
\hline & & & & & & & & & \multicolumn{2}{|c|}{ Bradykinin $\mathrm{ng} \cdot \mathrm{mL}^{-1}$} & \multicolumn{2}{|c|}{ Eosinophil \% } & \\
\hline & & & Pre & Post & Pre & Post & Pre & Post & Pre & Post & Pre & Post & \\
\hline 1 & 29 & M & 78.4 & 79.7 & 1.4 & 5.2 & 46 & 21 & 4.3 & 2.6 & 7.0 & 1.0 & None \\
\hline 2 & 29 & $\mathrm{M}$ & 98.0 & 98.5 & 1.4 & 2.0 & 70 & 40 & 4.9 & 5.3 & 16 & 1.0 & None \\
\hline 3 & 72 & $\mathrm{~F}$ & 133 & 160 & 2.2 & 4.6 & 40 & 23 & 4.2 & 1.8 & 80 & 3.0 & A \\
\hline 4 & 68 & $\mathrm{~F}$ & 89.2 & 99.4 & 6.2 & 8.2 & 72 & 20 & 4.2 & 3.3 & 40 & 0 & None \\
\hline 5 & 65 & $\mathrm{~F}$ & 65.1 & 91.0 & 0.50 & 0.50 & 90 & 22 & 4.8 & 3.0 & 9.0 & 0 & None \\
\hline 6 & 38 & $\mathrm{~F}$ & 92.4 & 98.2 & 6.0 & 6.2 & 198 & 60 & 9.6 & 2.9 & 50 & 20 & A \\
\hline 7 & 20 & $\mathrm{M}$ & 67.4 & 79.5 & 0.47 & 2.0 & 128 & 35 & 8.7 & 1.9 & 60 & 0 & A \\
\hline 8 & 63 & $\mathrm{~F}$ & 88.2 & 116 & 0.34 & 0.73 & 140 & 52 & 11 & 9.7 & 10 & 0 & A \\
\hline 9 & 66 & $\mathrm{~F}$ & 123 & 124 & 25 & 25 & 98 & 60 & 10 & 9.0 & 8.0 & 0 & $\mathrm{~A}, \mathrm{AC}$ \\
\hline 10 & 59 & $\mathrm{~F}$ & 118 & 118 & 1.1 & 1.2 & 60 & 30 & 7.0 & 6.0 & 18 & 0 & None \\
\hline 11 & 29 & $\mathrm{M}$ & 48.5 & 95.6 & 0.11 & 9.3 & 198 & 30 & 47 & 1.0 & 80 & 5.0 & A \\
\hline 12 & 46 & $\mathrm{M}$ & 96.2 & 107 & 6.0 & 12 & 320 & 250 & 40 & 30 & 70 & 15 & $A, B$ \\
\hline 13 & 29 & $\mathrm{M}$ & 72.9 & 80.6 & 0.25 & 0.60 & 193 & 46 & 6.6 & 2.2 & 50 & 2.0 & None \\
\hline 14 & 28 & M & 85.0 & 110 & 0.47 & 1.1 & 95 & 20 & 8.3 & 1.2 & 67 & 1.0 & None \\
\hline 15 & 46 & $\mathrm{~F}$ & 63.3 & 85.7 & 0.73 & 4.1 & 200 & 50 & 84 & 11 & 86 & 15 & None \\
\hline 16 & 32 & M & 128 & 129 & 2.9 & 3.2 & 20 & 16 & 2.5 & 2.0 & 5.0 & 0 & None \\
\hline 17 & 40 & $\mathrm{~F}$ & 100 & 149 & 2.1 & 21 & 282 & 51 & 5.0 & 0.5 & 71 & 0 & None \\
\hline 18 & 28 & $\mathrm{M}$ & 80.0 & 120 & 1.0 & 5.5 & 178 & 30 & 10 & 1.1 & 7.0 & 0 & None \\
\hline Mean & 43.7 & & 90.4 & 107.8 & 3.2 & 6.2 & 134.9 & 47.6 & 15.2 & 5.2 & 40.8 & 3.5 & \\
\hline SEM & 4.2 & & 5.7 & 5.6 & 1.4 & 1.7 & 20.6 & 12.7 & 5.1 & 1.7 & 7.4 & 1.5 & \\
\hline
\end{tabular}

FEV1: forced expiratory volume in one second; PD35: cumulative provocative dose of methacholine causing a $35 \%$ increase in respiratory resistance; ppb: parts per billion; pre: before steroid therapy; post: after steroid therapy; M: male; F: female; A: aminophylline; AC: anticholinergic agent; $\mathrm{B}$ : $\beta$-adrenergic agent.

\section{Measurement of nitric oxide concentration}

Exhaled NO levels were measured using a chemiluminescence analyser (Sievers Model 280NOA; Sievers, Boulder, CO, USA). Subjects were asked to perform a slow vital capacity manoeuvre at a constant flow of $2.5 \mathrm{~L} \cdot \mathrm{min}^{-1}$ and to maintain a constant expiratory oral pressure $(30$ $\mathrm{cmH}_{2} \mathrm{O}$ ) to close the velum, thus excluding nasal NO [20]. The exhaled air was absorbed at a sample flow of 200 $\mathrm{mL} \cdot \mathrm{min}^{-1}$. NO signals were simultaneously displayed on a chart recorder (Hewlett-Packard HP3396 SERIES III Integrator; Hewlett-Packard, Palo Alta, CA, USA) and compared with the signal generated from a calibration mixture of NO in nitrogen. At least two successive recordings at 2-min intervals were made and the mean of the peak values of two reproducible readings was used in the analysis of the results.

\section{Sputum induction and examination}

Fifteen minutes after fenoterol (400 $\mu \mathrm{g}$, inhalation) pretreatment, hypertonic saline $(4 \%)$ inhalation was performed using an ultrasonic nebulizer (MU-32; Sharp Co., Osaka, Japan). Since the samples contained saliva, this contamination was eliminated by both visual inspection and inverted microscope examination $[12,13]$. Hypertonic saline inhalation was continued for $15-30$ min until the sputum volume was $\sim 1 \mathrm{~mL}$. The nebulizer generated particles with a mean mass median aerodynamic diameter of $5.4 \mu \mathrm{m}$ at an output of $2.2 \mathrm{~mL} \cdot \mathrm{min}^{-1}$.

Ten microlitres of homogenized sputum was used for the eosinophil count. The remaining sputum samples were immediately mixed with saline, boiled to avoid degradation of bradykinin and stored at $-70^{\circ} \mathrm{C}$ until assay. The sputum samples $(1 \mathrm{~mL})$ for bradykinin assay were mixed with isopropyl alcohol $(2.5 \mathrm{~mL})$ and centrifuged for $10 \mathrm{~min}$ at $790 \times g$ at $4{ }^{\circ} \mathrm{C}$. The supernatant was mixed with petroleum ether $(2 \mathrm{~mL})$ and the upper layer aspirated; this manipulation was repeated. The lower layer was evaporated under nitrogen at $790 \times g$ at $55^{\circ} \mathrm{C}$, mixed with 50 $\mathrm{mM}$ tris (hydroxymethyl)aminomethane (Tris)- $\mathrm{HCl}(\mathrm{pH}$ 7.6) $(500 \mu \mathrm{L})$ and centrifuged for $5 \mathrm{~min}$ at $790 \times g$ at $4^{\circ} \mathrm{C}$. The sample $(400 \mu \mathrm{L})$ or standard bradykinin (Peptide Institute Inc., Osaka, Japan) was mixed with antibradykinin (100 $\mu \mathrm{L}$; SRL Inc., Tokyo, Japan) and incubated overnight at $4^{\circ} \mathrm{C}$. Next, they were incubated with ${ }^{125} \mathrm{I}_{\text {-tyr }}^{8}$ bradykinin (100 $\mu \mathrm{L}$; DuPont NEN Research Products, Boston, MA, USA) for $4 \mathrm{~h}$ at $4{ }^{\circ} \mathrm{C}$. The mixtures were mixed with $1 \% \gamma$-globulin $(100 \mu \mathrm{L})$ and $25 \%$ polyethylene glycol 6000 (mean molecular weight 7,500 Da; Wako Pure Chemical Industries, Osaka, Japan) $(700 \mathrm{~mL})$, and centrifuged for $10 \mathrm{~min}$ at $790 \times g$ at $4^{\circ} \mathrm{C}$, to separate the antibody-bound peptide from the free form. The supernatant was discarded, and the radioactivity in the pellet was measured using a gamma counter (1261 Multi Gamma; Wallac Oy, Turku, Finland). The sensitivity of this assay to immunoassayable bradykinin in saline was $1.0-3,000 \mathrm{pg}$. $\mathrm{mL}^{-1}$. If the bradykinin concentrations were above this range, the samples were diluted and measured again.

The percentage eosinophil reduction was determined from the difference in eosinophil counts before and after steroid therapy.

\section{Methacholine inhalation challenge}

Airway responsiveness to inhaled methacholine was measured using a device (Astograph TCK-6000CV; Chest Co.) that displays respiratory resistance $(R \mathrm{rs})$ measured via 
the forced oscillation method during tidal breathing with continuous inhalation of the aerosolized drug [21]. Briefly, it consists of an aerosol delivery system, a loudspeaker box system which generates a constant-amplitude sine wave pressure at $3 \mathrm{~Hz}$, and a system for measuring $R \mathrm{rs}$ automatically from mouth flow and mouth pressure. Aerosols were generated by a Bird nebulizer (Bird Corp., Palm Springs, CA, USA), each containing $4 \mathrm{~mL}$ of solution driven with a constant airflow of $6 \mathrm{~L} \cdot \mathrm{min}^{-1}$ by an air compressor to elicit an output of $\sim 0.15 \mathrm{~mL} \cdot \mathrm{min}^{-1}$. The output was determined by measuring the change in weight of the nebulizer chamber. Methacholine (Sigma Chemical Co., St Louis, MO, USA) was prepared in $0.9 \%$ saline in two-fold increasing concentrations ranging $0.049-25 \mathrm{mg} \cdot \mathrm{mL}^{-1}$. After it was confirmed that a 1min inhalation of saline did not change the baseline $R \mathrm{rs}$, each concentration of methacholine solution was inhaled for 1 min until Rrs reached approximately twice the baseline value or until the maximum concentration was administered. The index of the airway responsiveness was defined as the cumulative provocative dose of methacholine causing a $35 \%$ increase in $R$ rs (PD35).

\section{Study protocol}

On the first day, after exhaled NO and FEV1 measurement, sputum induction was carried out. The methacholine inhalation challenge test was performed on a separate day. After baseline value assessment, open unblinded uncontrolled steroid inhalation therapy $(800 \mu \mathrm{g}$ beclomethasone $\cdot$ day $^{-1}$ ) was administered to all subjects for 8 weeks, and then the same examination was repeated. All bronchodilator therapies were stopped $\geq 24 \mathrm{~h}$ before the examination.

\section{Statistical analysis}

A linear regression analysis was performed using the method of least squares. The PD35 was log-transformed in the analysis. A p-value of $<0.05$ was considered significant.

\section{Results}

Baseline airway calibre, inflammatory indices and $\mathrm{cu}$ mulative provocative dose of methacholine causing a $35 \%$ increase in respiratory resistance

The baseline FEV1 of the enrolled subjects were normal to moderate (48.5-133\% of the predicted value) and all subjects showed enhanced airway responsiveness (PD35 $\left.0.25-25 \mathrm{mg} \cdot \mathrm{mL}^{-1}\right)($ table 1$)$. All airway inflammatory indices, namely bradykinin concentration, percentage of eosinophils in the induced sputum and exhaled NO concentration, were elevated in all subjects (table 1).

The results of multiple regression analysis of airway responsiveness (PD35) and baseline airway calibre (FEV1 $\%$ pred) against inflammatory indices are summarized in table 2 . The FEV1 was inversely related to both exhaled NO levels $(p<0.05)$ and bradykinin concentration in the induced sputum $(\mathrm{p}<0.05)$ but not to the percentage of eosinophils in the induced sputum. In contrast, the PD35 had no significant correlation with any of the airway inflammatory indices.
Table 2. - Correlation between airway inflammatory indices and physiological parameters

\begin{tabular}{|c|c|c|c|c|}
\hline & \multicolumn{2}{|c|}{ PD35 } & \multicolumn{2}{|c|}{ FEV1 } \\
\hline & Pre & Post & Pre & Post \\
\hline $\begin{array}{l}\text { Exhaled NO con- } \\
\text { centration }\end{array}$ & $-0.17 \mathrm{NS}$ & $0.32 \mathrm{NS}$ & $\begin{array}{l}-0.53 \\
<0.05\end{array}$ & $-0.04 \mathrm{NS}$ \\
\hline $\begin{array}{l}\text { Bradykinin concentra- } \\
\text { tion in induced sputum }\end{array}$ & $-0.22 \mathrm{NS}$ & $0 \mathrm{NS}$ & $\begin{array}{l}-0.48 \\
<0.05\end{array}$ & $-0.22 \mathrm{NS}$ \\
\hline $\begin{array}{l}\text { Eosinophils }(\%) \text { in } \\
\text { induced sputum }\end{array}$ & $-0.30 \mathrm{NS}$ & $0.26 \mathrm{NS}$ & $-0.30 \mathrm{NS}$ & $-0.21 \mathrm{NS}$ \\
\hline
\end{tabular}

PD35: cumulative provocative dose of methacholine causing a $35 \%$ increase in respiratory resistance, which was log transformed in the analysis; FEV1: forced expiratory volume in one second (percentage of the predicted value); pre: before steroid therapy; post: after steroid therapy; Ns: nonsignificant.

As shown in figure 1, baseline FEV1 andPD35 correlated positively $(\mathrm{p}<0.01)$. However, there was no significant correlation between PD35 and any of the AIIs.

\section{Effect of steroid inhalation therapy}

Eight weeks' steroid inhalation therapy improved FEV1 and PD35 as well as airway inflammatory indices (table 1). In contrast to the data before steroid administration, the significant correlation between FEV1 (\% pred) and inflammatory parameters such as exhaled NO levels and bradykinin concentration in the sputum disappeared after steroid treatment (table 2). The percentage increase in FEV1 after steroid therapy correlated significantly with the reduction in bradykinin concentration $(p<0.01)$ and eosinophil counts $(\mathrm{p}<0.01)$ in the induced sputum and exhaled NO concentration $(p<0.01)$ (fig. 2$)$. The degree of PD35 improvement after steroid treatment also correlated significantly with the reductions in the above three airway inflammatory indices $(\mathrm{p}<0.01$ for each) (fig. 3). Further, the steroid-mediated PD35 improvement correlated significantly with the percentage increase in FEV1 after steroid therapy $(\mathrm{p}<0.01)$ (fig. 4$)$.

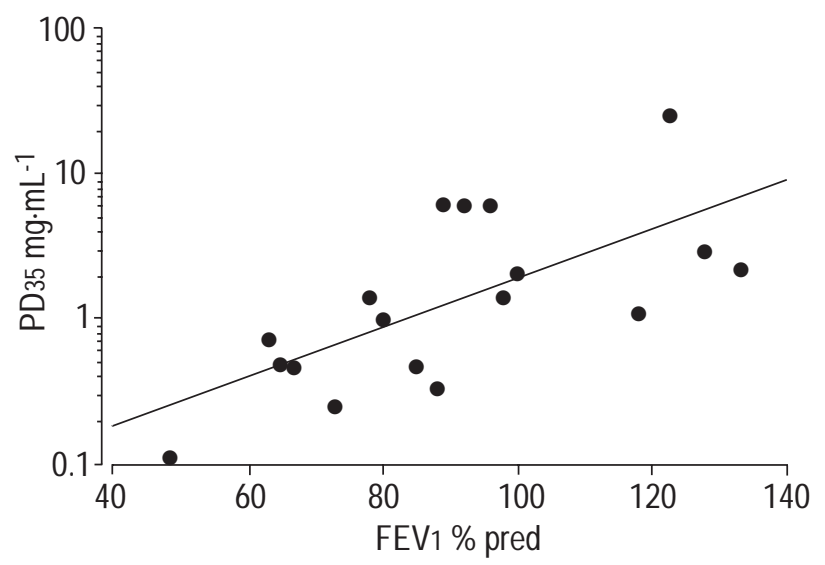

Fig. 1. - Baseline forced expiratory volume in one second (FEV1) and airway responsiveness to methacholine (cumulative provocative dose of methacholine causing a 35\% increase in respiratory resistance (PD35)). The line corresponds to the fitted regression equation $(r=0.67, \mathrm{p}<0.01)$. 
a)

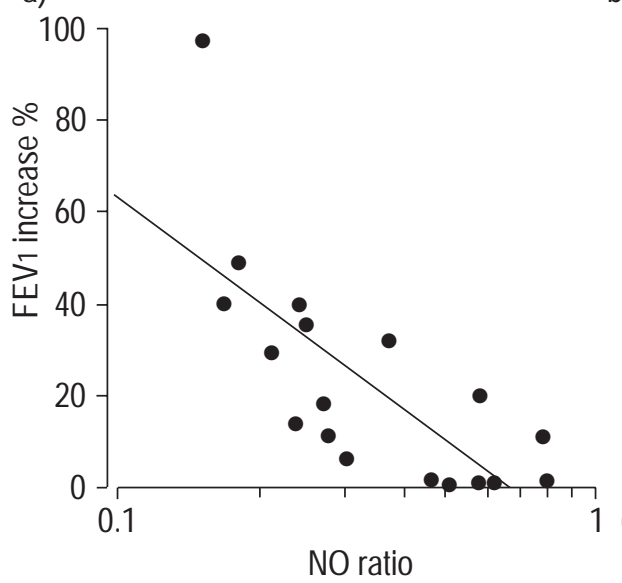

b)

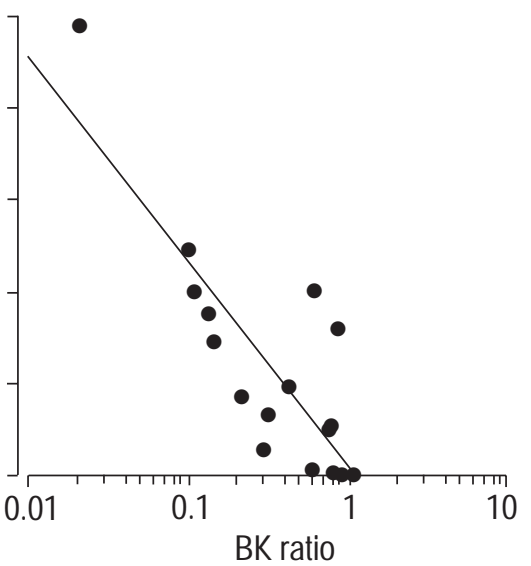

c)

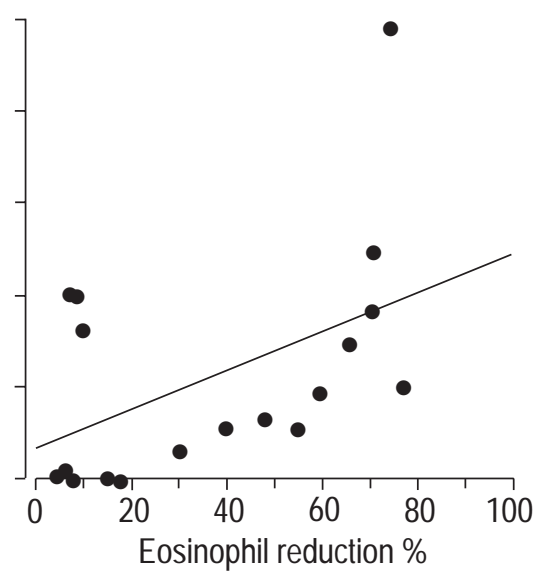

Fig. 2. - Relationship between steroid-mediated improvement in airway calibre (percentage increase in forced expiratory volume in one second (FEV1)) and airway inflammatory indices: the ratio of a) nitric oxide (NO) in exhaled gas $(\mathrm{r}=-0.73, \mathrm{p}<0.001)$ and $\mathrm{b})$ bradykinin $(\mathrm{BK})$ in induced sputum $(\mathrm{r}=-0.84$, $\mathrm{p}<0.001$ ) (post-steroid level/pre-steroid level); and c) percentage eosinophil reduction in induced sputum (difference in eosinophil counts before and after steroid therapy) $(\mathrm{r}=0.48, \mathrm{p}<0.05)$. The lines correspond to the fitted regression equation.

\section{Discussion}

It has been demonstrated that, in asthmatic subjects: 1) airway responsiveness to methacholine correlated positively with baseline airway diameter but not with airway inflammatory indices such as exhaled NO levels, eosinophil counts and bradykinin concentration in induced sputum; 2) 8 weeks' uncontrolled steroid inhalation therapy improved both airway calibre and responsiveness in proportion to the reduction in the airway inflammatory parameters; and 3) the improvement in airway responsiveness after steroid therapy significantly correlated with the improvement in airway diameter.

Asthma is defined by three characteristic features, namely intermittent reversible airway obstruction, AHR and airway inflammation [2]. In the present study, baseline airway responsiveness correlated significantly with baseline airway calibre, in agreement with a previous study
[22], suggesting that airway geometric factors are involved in the mechanisms of AHR in asthmatics. The underlying mechanisms of the airway calibre reduction observed in asthmatic subjects may be due to airway inflammation $[1,2]$. In the present study, it was observed that two of three inflammatory indices, i.e. exhaled NO levels and sputum bradykinin concentration, showed a significant inverse relation with airway calibre, supporting the above hypothesis.

In contrast to the significant relationship between airway calibre and responsiveness, the three airway inflammatory parameters employed in the present study, namely sputum eosinophil counts, exhaled NO levels and bradykinin concentration in sputum, exhibited no significant relationship with airway responsiveness. To date, the relationship between airway responsiveness and inflammatory cells, such as eosinophil recruitment into the airways, has been the subject of much controversy. Some reports have shown a)

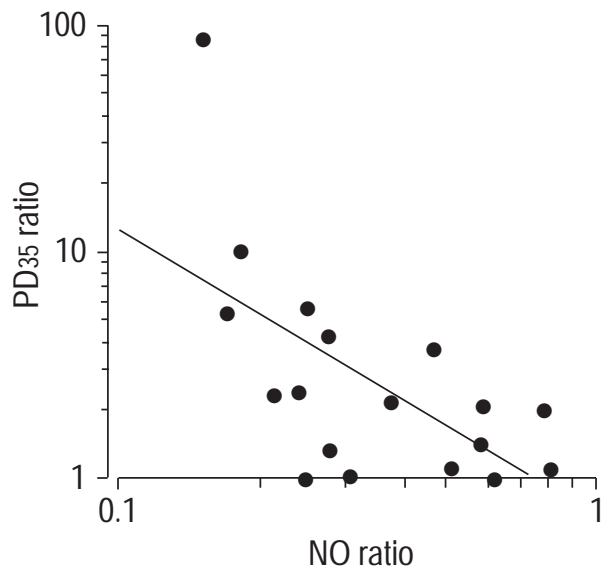

b)

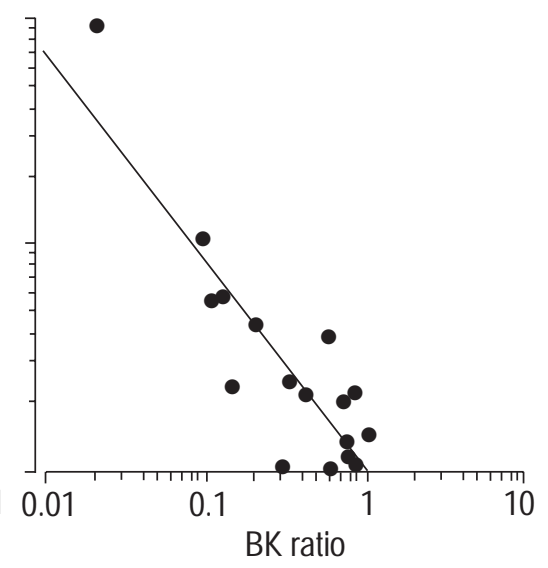

c)

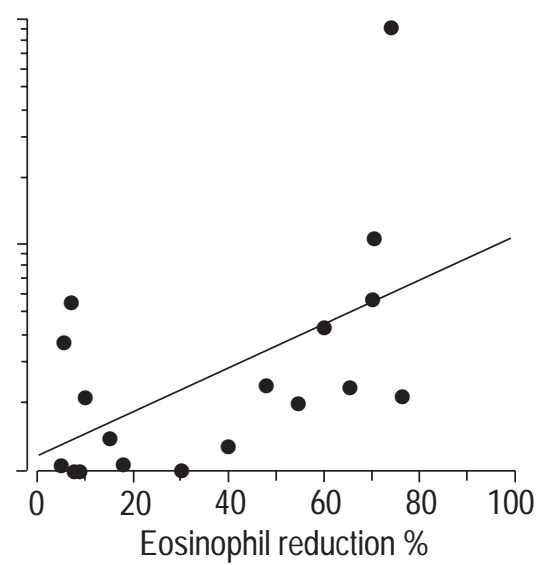

Fig. 3. - Relationship between steroid-mediated improvement in airway responsiveness to methacholine (cumulative provocative dose of methacholine causing a $35 \%$ increase in respiratory resistance (PD35)) and airway inflammatory indices: the ratio of a) nitric oxide (NO) in exhaled gas ( $r=-0.61$, $\mathrm{p}<0.01)$ and $\mathrm{b}$ ) bradykinin $(\mathrm{BK})$ in induced sputum $(\mathrm{r}=-0.88, \mathrm{p}<0.001)$ (post-steroid level/pre-steroid level); and $\mathrm{c})$ percentage eosinophil reduction in induced sputum (difference in eosinophil counts before and after steroid therapy) $(\mathrm{r}=0.55, \mathrm{p}<0.05)$. The PD35 ratio was the ratio of post-steroid PD35 to pre-steroid PD35. The lines correspond to the fitted regression equation. 


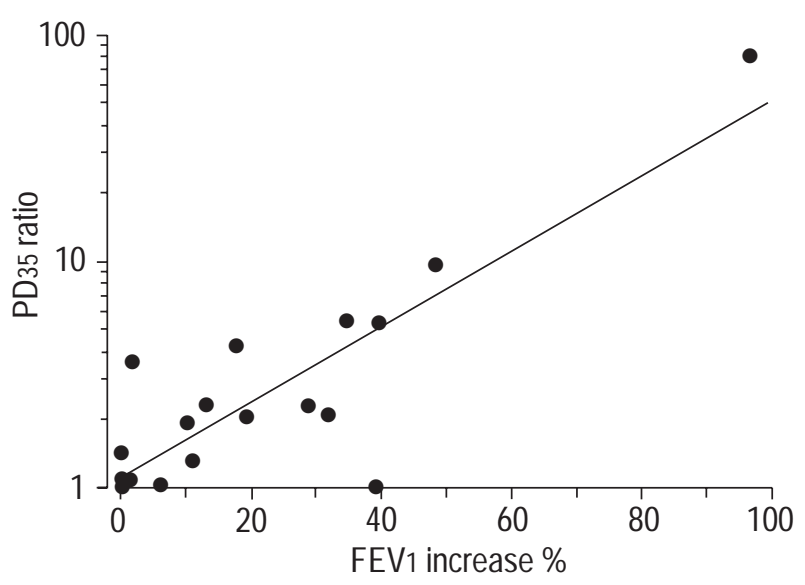

Fig. 4. - Relationship between steroid-mediated improvement in airway responsiveness to methacholine (cumulative provocative dose of methacholine causing a 35\% increase in respiratory resistance (PD35), poststeroid PD35/pre-steroid PD35) and airway calibre (percentage increase in forced expiratory volume in one second (FEV1)). The line corresponds to the fitted regression equation $(\mathrm{r}=0.85, \mathrm{p}<0.001)$.

a positive relationship between the presence of inflammatory cells and enhanced airway responsiveness [3-6], whereas others have failed to establish such a relationship [7-11]. The present data is compatible with the latter reports.

It has been reported that NO production is exaggerated in asthmatic airways [15], and there is increasing evidence that high concentrations of NO may contribute to asthmatic airway inflammation via development of the Thelper 2 lymphocyte response and through chemotaxis of eosinophils $[23,24]$. A recent report has demonstrated that exhaled NO levels show a significant correlation with airway responsiveness, i.e. asthmatic subjects with higher NO concentrations show more enhanced airway responsiveness [25], which is in contrast to the present results.

Bradykinin has potent inflammatory action [26-28] and its upregulation has been reported in asthmatic airways $[17,18]$. The present study is the first report examining the relationship between airway responsiveness and bradykinin concentration in the airways, and no significant relation between the two was found.

A possible explanation for the lack of association between airway inflammation and responsiveness may be as follows. Airway inflammation seems to cause airway hyperresponsiveness via two mechanisms [2]. One mechanism is through the release of chemical mediators end the other is via cytokine and chemokine mechanisms. The former mechanism affects airway function for a short duration. In contrast, the later mechanism works for a relatively longer duration via recruitment of additional inflammatory cells and modification of airway resident cells, such as epithelial cells and airway smooth muscle cells, resulting in airway remodelling [2]. Baseline airway responsiveness is likely to be determined by two factors, one of which is active inflammation and the other airway remodelling. Airway inflammation assessment by means of exhaled NO levels and sputum examination (eosinophil counts and bradykinin concentration) may well reflect the former component but not the latter. Therefore, although airway inflammation contributes greatly to airway hyperresponsiveness in asthmatic subjects [1], the two phenomena have often appeared dissociated. This hypothesis may be supported by the present steroid treatment data.

In the present study, 8 weeks' uncontrolled steroid treatment largely improved airway responsiveness, as has also been shown in previous studies [29, 30]. The improvement in airway responsiveness after steroid therapy correlated well with each inflammatory parameter change after steroid therapy, suggesting that the steroid-sensitive component, in other words the reversible component of airway responsiveness, in asthmatic subjects, depends upon the degree of reduction in airway inflammatory changes. Although steroid treatment largely reduced airway responsiveness as well as inflammatory indices, airway hyperresponsiveness was still observed even after treatment. The persistent airway hyperresponsiveness may be due to airway remodelling and other mechanisms such as those due to genetic factors.

In conclusion, it has been shown that airway responsiveness exhibits significant correlation with baseline airway calibre but not with airway inflammatory parameters such as exhaled NO levels, eosinophil counts and bradykinin concentration in the airways. The improvement in airway diameter and responsiveness during uncontrolled therapy with inhaled steroids depends upon the degree of reduction in the above three airway inflammatory indices. Because the changes in airway calibre and responsiveness show a significant positive relationship, steroid therapy may change airway responsiveness, at least in part, via a reduction in airway narrowing. The latter requires further, placebo-controlled study.

\footnotetext{
Acknowledgements. The authors thank B. Bell for reading the manuscript.
}

\section{References}

1. Sheffer AL, ed. Global Initiative for Asthma: global strategy for asthma management and prevention. National Heart, Lung and Blood Institute/World Health Organization Workshop report. National Institute of Health publication No.95-3659. National Institute of Health, National Heart, Lung and Blood Institute; 1995.

2. Haley KJ, Drazen JM. Inflammation and airway function in asthma: what you see is not necessarily what you get. Am J Respir Crit Care Med 1998; 157: 1-3.

3. Kirby JG, Hargreave EF, Gleich GJ, O'Byrne PM. Bronchoalveolar cell profiles of asthmatic and nonasthmatic subjects. Am Rev Respir Dis 1987; 136: 379-383.

4. Wardlaw AJ, Dunnette S, Gleich GJ, Collins JV, Kay AB. Eosinophils and mast cells in bronchoalveolar lavage in subjects with mild asthma: relationship to bronchial hyperreactivity. Am Rev Respir Dis 1983; 137: 62-69.

5. Azzawi M, Bradley B, Jeffery PK, et al. Identification of active $\mathrm{T}$ lymphocytes and eosinophils in bronchial biopsies in stable atopic asthma. Am Rev Respir Dis 1990; 142: 1407-1413.

6. Bentley AM, Menz G, Stortz C, et al. Identification of T lymphocytes, macrophages, and activated eosinophils in the bronchial mucosa in intrinsic asthma: relationship to symptoms and bronchial responsiveness. Am Rev Respir Dis 1992; 146: 500-506. 
7. Jeffery PK, Wardlaw AJ, Nelson FC, Collins JV, Kay AB Bronchial biopsies in asthma: an ultrastructual, quantitative study and correlation with hyperreactivity. Am Rev Respir Dis 1989; 140: 1745-1753.

8. Adelroth E, Rosenhall L, Johansson SA, Linden M, Venge P. Inflammatory cells and eosinophilic activity in asthmatics investigated by bronchoalveolar lavage: the effects of antiasthmatic treatment with budesonide or terbutaline. Am Rev Respir Dis 1990; 142: 91-99.

9. Djukanovic R, Wilson JW, Britten KM, et al. Quantitation of mast cells and eosinophils in the bronchial mucosa of symptomatic atopic asthmatics and healthy control subjects using immunohistochemistry. Am Rev Respir Dis 1990; 142: 863-871.

10. Ollerenshaw SL, Woolcock AJ. Characteristics of the inflammation in biopsies from large airways of subjects with asthma end subjects with airflow limitation. Am Rev Respir Dis 1992; 145: 922-927.

11. Crimi E, Spanevello A, Neri M, Ind PW, Rossi GA, Brusasco V. Dissociation between airway inflammation and airway hyperresponsiveness in allergic asthma. Am J Respir Crit Care Med 1998; 157: 4-9.

12. Pin I, Gibson PG, Kolendowicz R, et al. Use of induced sputum cell counts to investigate airway inflammation in asthma. Thorax 1992; 47: 25-29.

13. Tomaki M, Ichinose M, Miura M, et al. Elevated substance $\mathrm{P}$ content in induced sputum from patients with asthma and patients with chronic bronchitis. Am J Respir Crit Care Med 1995; 151: 613-617.

14. Pizzichini E, Pizzichini MMM, Efthimiadis A, et al. Indices of airway inflammation in induced sputum: reproducibility and validity of cell and fluid-phase measurements. Am J Respir Crit Care Med 1996; 154: 303-317.

15. Kharitonov SA, Yates D, Robbins RA, Logan-Sinclair R, Shinebourne EA, Barnes PJ. Increased nitric oxide in exhaled air of asthmatic patients. Lancet 1994; 343: 133135.

16. Barnes PJ. NO or no NO in asthma? Thorax 1996; 51: 218-220.

17. Christiansen SC, Proud D, Cochrane CG. Detection of tissue kallikrein in the bronchoalveolar lavage fluid of asthmatic subjects. J Clin Invest 1987; 79: 188-197.

18. Christiansen SC, Proud D, Sarnoff RB, Juergens U, Cochrane CG, Zuraw BL. Elevation of tissue kallikrein and kinin in the airways of asthmatic subjects after endo- bronchial allergen challenge. Am Rev Respir Dis 1992; 145: 900-905.

19. American Thoracic Society. Standards for the diagnosis and care of patients with chronic obstructive pulmonary disease (COPD) and asthma. Am Rev Respir Dis 1987; 136: 225-244.

20. Silkoff PE, McClean PA, Slutsky AS, et al. Marked flowdependence of exhaled nitric oxide using a new technique to exclude nasal nitric oxide. Am J Respir Crit Care Med 1997; 155: 260-267.

21. Takishima T, Hida W, Sasaki H, Suzuki S, Sasaki T. Direct writing recorder of the dose-response curves of the airway to methacholine. Chest 1981; 80: 600-606.

22. Benson MK. Bronchial hyperreactivity. Br J Dis Chest 1975; 69: 227-239.

23. Barnes PJ, Liew FY. Nitric oxide and asthmatic inflammation. Immunol Today 1995; 16: 128-130.

24. Barnes PJ. Nitric oxide. In: Barnes PJ, Rodger IW, Thomson NC, eds. Asthma: Basic Mechanisms and Clinical Management. 3rd Edn. New York, Academic Press, 1998; pp. 369-388.

25. Dupont LJ, Rochette F, Demedts MG, Verleden GM. Exhaled nitric oxide correlates with airway hyperresponsiveness in steroid-naive patients with mild asthma. Am J Respir Crit Care Med 1998; 157: 894-898.

26. Ichinose M, Barnes PJ. Bradykinin-induced airway microvascular leakage and bronchoconstriction are mediated via a bradykinin B2 receptor. Am Rev Respir Dis 1990; 142: 1104-1107.

27. Nakajima N, Ichinose M, Takahashi T, et al. Bradykinininduced airway inflammation: contribution of sensory neuropeptides differs according to airway site. $A m J$ Respir Crit Care Med 1994; 149: 694-698.

28. Proud DL. Kinins. In: Barnes PJ, Rodger IW, Thomson NC, eds. Asthma: Basic Mechanisms and Clinical Management. 3rd Edn. New York, Academic Press, 1998; pp. 297-307.

29. Bhaget RG, Grunstein MM. Effect of corticosteroids on bronchial responsiveness to methacholine in asthmatic children. Am Rev Respir Dis 1985; 131: 902-906.

30. Kerrebijn KF, van Essen-Zandvliet EEM, Neijens HJ. Effects of long-term treatment with inhaled corticosteroids and beta-agonists on the bronchial responsiveness in children with asthma. J Allergy Clin Immunol 1987; 79: 653-659. 